\title{
Action of nonsteroidal, anti-inflammatory drugs on human and rat peripheral leucocyte migration in vitro
}

\author{
K. A. BROWN AND A. J. COLLINS
}

From the Department of Pharmacology, University of Bath, and Royal National Hospital for Rheumatic Diseases, Bath

SUMMARY Using an in vitro system of cell migration from glass capillary tubes, the nonsteroidal, anti-inflammatory agents sodium salicylate, aspirin, ibuprofen, phenylbutazone, and indomethacin were shown to inhibit the migration of human peripheral leucocytes in a dose-related manner. This drug action was not confined to one species, as shown by the modification of rat peripheral leucocyte motility by sodium salicylate and aspirin. The relevance of the human findings to the clinical effectiveness of these agents is discussed.

An increase in capillary permeability followed by a leucocytic exudation to remove the inciting agent and/or damaged tissue, constitute two of the main morphological events of an inflammatory response. Leucocyte participation, in particular the polymorphonuclear cells, is not only confined to an acute inflammatory episode, such as gout, but also extends to the chronic inflammatory reaction as in rheumatoid arthritis. Should leucocyte infiltration into an inflammatory focus be restricted, then the powerful mediators that these cells are capable of releasing would be impeded and the inflammation suppressed.

The inhibition by indomethacin of an inflamed dog knee joint, initiated by the deposition of sodium urate crystals, has been correlated with a decreased fluid exudate and polymorphonuclear cell accumulation (Phelps and McCarty, 1967). The authors concluded that the mode of drug action was a direct inhibitory effect on the movement of the invading polymorphonuclear cell.

In the rat, carrageenan-induced oedema Van Arman et al., (1971) showed that an anti-oedematous dose of indomethacin reduced the number of mobilized neutrophils. Similarly, an analogous finding was obtained with aspirin (Vinegar et al., 1971) and other nonsteroidal anti-inflammatory drugs ( $\mathrm{Di}$ Rosa et al. 1971; Nakanishi and Kazuhiro, 1974). However, objection to the hypothesis that nonsteroidal, anti-inflammatory drugs (NSAID) inhibited cell movement, stemmed from the failure

Accepted for publication September 12, 1976

Correspondence to Dr. K. A. Brown, Bone and Joint Research Unit, ARC Building, London Hospital Medical College, Turner Street, London E1 2AD. of indomethacin to reduce polymorphonuclear cell infiltration in the local Schwartzman reaction (Van Arman et al., 1970), together with the failure of phenylbutazone and indomethacin to modify the in vitro chemotactic activity of rabbit and human polymorphonuclear cells (Keller and Sorkin, 1965; Borel, 1973).

Using a technique originally described in the Leucocyte Migration Test (George and Vaughan, 1962), the action of several NSAID agents were investigated on the in vitro migration of human and rat peripheral leucocytes. Previously a similar system had shown NSAID to suppress the movement of rat peritoneal leucocytes (Di Rosa, 1974).

\section{Methods}

PREPARATION OF HUMAN PERIPHERAL LEUCOCYTES From each subject, $20 \mathrm{ml}$ of blood were collected from a cubital vein into a syringe containing 400 units heparin. After centrifugation at $800 \mathrm{~g}$ for 10 minutes, the plasma and leucocyte layer were transferred to a clean syringe which was stood upright in a $37^{\circ} \mathrm{C}$ incubator. After 1 hour of incubation, during which most of the remaining erthrocytes had spontaneously sedimented, the leucocyte-rich plasma was aspirated and centrifuged at $240 \mathrm{~g}$ for 10 minutes. The leucocytes were washed twice with Hanks's Balanced Salt Solution (HBSS) (pH 7.35) and adjusted to a final concentration of $4 \times 10^{7}$ cells $/ \mathrm{ml}$.

PREPARATION OF RAT PERIPHERAL LEUCOCYTES Blood was obtained from ether-anaesthetized male 
Wistar rats, either by withdrawal from the ventral aorta or by cardiac puncture. Unlike human erythrocytes, rat erythrocytes do not sediment spontaneously and, consequently, $3 \%$ solutions of the sediment-inducing agent dextran (MW 200000 250000 ), containing $0.9 \% \mathrm{NaCl}$ and 20 units $/ \mathrm{ml}$ heparin, were added in equal volumes to each rat's blood sample. After incubation at $37^{\circ} \mathrm{C}$ for 1 hour, leucocytes from 15 rats were pooled. After washing twice with HBSS, the final cell suspension was adjusted to a concentration of $1 \times 10^{8}$ cells $/ \mathrm{ml}$.

\section{MIGRATION OF LE UCOCYTES FROM CAPILLARY TUBES}

Ths method was modified from that described by Maini et al. (1973). Leucocytes, prepared as above, were packed into glass capillary tubes (Drummonde, diameter $0.4 \mathrm{~mm}$, length $75 \mathrm{~mm}$ ), sealed at one end, and centrifuged at $2400 \mathrm{~g}$ for 5 minutes. Each capillary tube was cut at the resultant cell-supernatant interface and its leucocyte pellet mounted into migration chambers (Sterilin) containing tissue culture media composed of $10 \%$ horse serum, Eagles's medium (MEM) and $100 \mathrm{IU} / \mathrm{ml}$ penicillinstreptomycin, buffered with $20 \mathrm{mmol} / 1$ Hepes buffer to a final $\mathrm{pH}$ of $7 \cdot 35$. Chambers were rendered air-tight by applying cover-slips on to previously greased edges. At least four replicate chambers were prepared for every drug concentration investigated. All migration plates, which contained 12 chambers each, were carefully layered on to perfectly horizontal incubator shelves and left for 20 hours at $37^{\circ} \mathrm{C}$.

At the end of this incubation period, the cells had migrated out from the tube along the floor of the chamber in a fan-like fashion. Each cell migration was projected on to paper by a photographic enlarger, its image drawn, and area measured by planimetry.

There was no change in the media $\mathrm{pH}$ of either control (i.e. chambers without a drug present) or drug-containing chambers. Cell viability, as determined by the trypan-blue exclusion test, was always $>9.5 \%$.

\section{PRE PARATION OF DR UG SOLUTIONS}

All NSAID investigated were dissolved and buffered in tissue culture media to a final $\mathrm{pH}$ of $7 \cdot 35$ and passed through a $0.45 \mu \mathrm{m}$ filter into sterile glassware. Each drug solution was prepared freshly before starting a migration study and serial dilutions made under aseptic conditions.

\section{Subjects studied}

Initial studies had found the human leucocyte migration response to an anti-inflammatory agent to be independent of an age or sex difference. Each drug was investigated on leucocytes prepared from at least 6 healthy subjects of both sexes, whose ages? varied from 20-50 years and who were not receiving any current drug therapy.

\section{Results}

All in vitro effects of the NSAID on cellular migra tion were expressed as a percentage inhibition otes stimulation of the control migration areas. Student's' $t$ ' test was used to assess any significant difference from control and drug-containing chambers.

In the human studies, sodium salicylate, aspirin ibuprofen, indomethacin, and phenylbutazone in hibited cell movement in a dose-related manner. Phenylbutazone at $1 \times 10^{-4} \mathrm{~mol} / 1$ induced a mean $14 \%$ inhibition of migration $(P<0.002)$, while ati lower concentrations no further suppression of cello movement was demonstrable (Fig. 1a). In contrase to the fairly consistent migration response of theindividual's leucocytes to phenylbutazone was the response elicited towards indomethacin; inhibition of migration at $1 \times 10^{-3} \mathrm{~mol} / 1$ varying from $34 \%$ to $100 \%$ of the control values (Fig. $1 b$ ). Compared with the other NSAID, indomethacin produced the most persistent inhibitory activity over a large dilutions spectrum. Although indomethacin at $1 \times 10^{-5} \mathrm{~mol} / \mathrm{E}$ produced a mean $5 \%$ inhibition of migration (nonsignificant), leucocytes from 5 individuals expressed a mean $10 \%$ inhibition $(P<0.02)$ at this dilution.

Ibuprofen (Fig. 1c) elicited a mean $94 \%$ inhibition of leucocyte migration at $1 \times 10^{-2} \mathrm{~mol} / 1,36 \%$ inhibi? tion at $1 \times 10^{-3} \mathrm{~mol} / \mathrm{l}(\mathrm{P}<0.001)$, and $14 \%$ inhibition? at $5 \times 10^{-4} \mathrm{~mol} / \mathrm{l}(\mathrm{P}<0.01)$, further dilutions failingy to modify leucocyte motility. At the highest concen? tration investigated $1 \times 10^{-2} \mathrm{~mol} / 1$ aspirin (Fig. $1 d$ 送 produced a wide variation in the inhibitory migration response (40-100\%), a finding that was not compar? able with the salicylate studies (Fig. 1e). Also, at $1 \times 10^{-3} \mathrm{~mol} / 1$ aspirin induced a mean $27 \%$ inhibition of leucocyte movement $(\mathrm{P}<0.002)$ compared to $a \mathrm{P}$ mean $15.5 \%$ produced by salicylate at the equivalent concentration $(P<0 \cdot 01)$. Apart from one experi ment, in which aspirin stimulated leucocyte motility at $1 \times 10^{-4} \mathrm{~mol} / 1$ and $1 \times 10^{-5} \mathrm{~mol} / \mathrm{l}$, no further significant modification of cell movement wasw recorded from either the salicylate or aspirin studies at lower drug dilutions.

Paracetamol (Fig. 1f) showed a mean $49 \%$ inhibition of migration at $1 \times 10^{-2} \mathrm{~mol} / 1$ and a $22 \%$ inhibition at $5 \times 10^{-3} \mathrm{~mol} / 1(\mathrm{P}<0 \cdot 01)$. Although not shown graphically, over the spectrum $1 \times 10^{-2} \mathrm{~mol} / \mathrm{P}$ to $1 \times 10^{-8} \mathrm{~mol} / 1$ para-hydroxybenzoic acid pro疋 duced no statistical modification of leucocyte motility. 

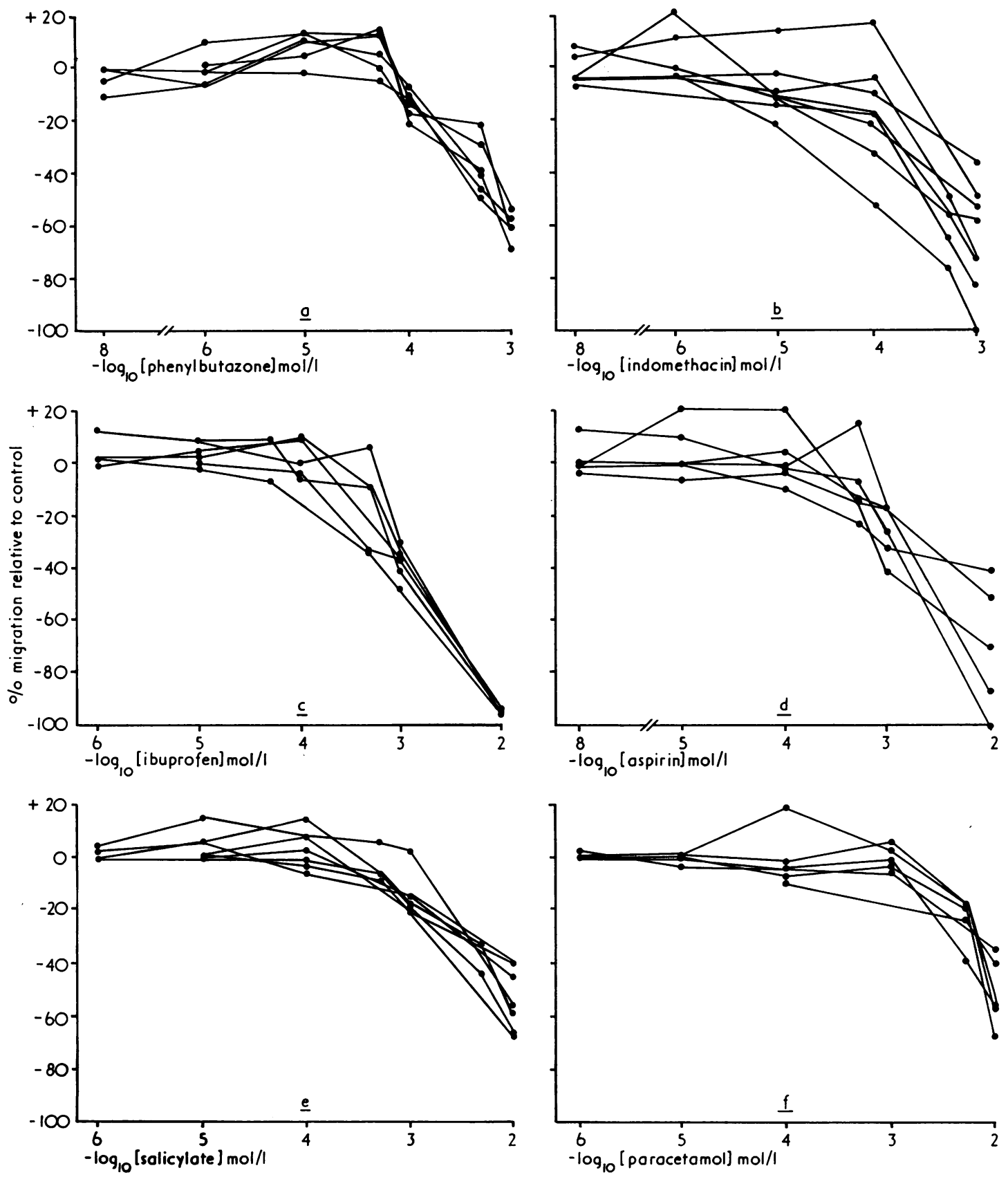

Fig. 1 Elfect in vitro of $(a)$ phenylbutazone, $(b)$ indomethacin, (c) ibuprofen, $(d)$ aspirin, $(e)$ salicylate, and $(f)$ paracetamol on human peripheral leucocyte migration. Each curve illustrates the leucocyte migration response of one individual and every point on that curve the mean response of at least four migration areas. The standard error of the mean (not shown) for each determination was always $<1 \cdot 0$. 
Taking the molar concentration of salicylate which produced $50 \%$ inhibition as unity, the relative potencies of the other NSAID were calculated graphically from their ID 50 values. From the Table the list in decreasing order of potency was indomethacin $>$ phenylbutazone $>$ ibuprofen $>$ aspirin $>$ salicylate.

Table Relative potencies of NSAID on total human leucocyte migration in vitro

\begin{tabular}{lcl}
\hline NSAID & Potency figure & $\begin{array}{l}\text { Molar concentration at } \\
\text { IDSO (mol/l) }\end{array}$ \\
\hline Salicylate & 1 & $8.0 \times 10^{-3}$ \\
Aspirin & 2.5 & $3.2 \times 10^{-3}$ \\
Ibuprofen & 5 & $1.7 \times 10^{-3}$ \\
Phenylbutazone & 11 & $7.0 \times 10^{-4}$ \\
Indomethacin & 13 & $6.3 \times 10^{-4}$
\end{tabular}

A potency figure of 1 was arbitrarily assigned to the concentration of salicylate which produced $50 \%$ inhibition (ID50) of leucocyte migration. The relative potencies of the other NSAID were calculated graphically from their ID50 values

NSAID $=$ nonsteroidal anti-inflammatory drugs.

In the animal studies two different groups of rats were used. The first was comprised of male Wistar rats weighing 220-290 g, and the second of rats weighing $350-430 \mathrm{~g}$ of the same sex and strain. At least eight capillary tubes were prepared for each drug dilution.

The extent of suppression induced by sodium salicylate at a range of $1 \times 10^{-2} \mathrm{~mol} / 1$ to $1 \times 10^{-3}$ $\mathrm{mol} / \mathrm{l}$ on the in vitro migration of rat peripheral leucocytes was well complemented in both groups (Fig. 2). Leucocytes of group 2 were persistently inhibited in movement at lower concentrations (approximately $20 \%$ inhibition from $1 \times 10^{-3} \mathrm{~mol} / 1$ to $1 \times 10^{-5} \mathrm{~mol} / 1(\mathrm{P}<0.05)$, while cells of group 1 were stimulated to a $23 \%$ increase $(\mathrm{P}<0.001)$ of their control migration areas in $1 \times 10^{-5} \mathrm{~mol} / \mathrm{l}$ salicylate.

Though aspirin elicited a mean $52 \%$ migration inhibition at $5 \times 10^{-3} \mathrm{~mol} / 1$ in both groups, thereafter the cellular response of each group to lower concentrations was markedly varied. Group 1 leucocytes showed marked stimulation, culminating in a $31 \%$ increase of migration at $1 \times 10^{-5} \mathrm{~mol} / 1(\mathrm{P}<0.001)$, while the migration responsiveness of group 2 leucocytes produced an inconsistent profile.

\section{Discussion}

All NSAID investigated inhibited the in vitro migration of human and rat peripheral leucocytes in a dose-related manner. The finding that indomethacin was the most potent drug studied agrees with the work of Di Rosa (1974). However, leucocytes used by Di Rosa were collected from the rat peritoneal cavity and were comprised mainly of

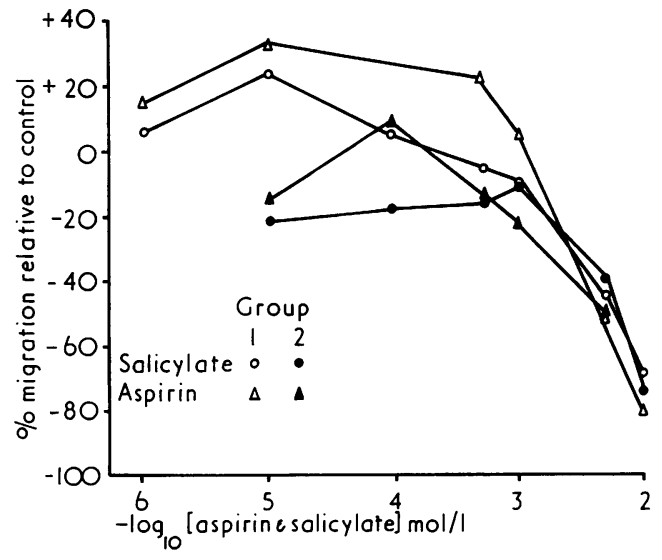

Fig. 2 Effect of aspirin and salicylate in vitro on rat peripheral leucocyte migration. Group 1 was comprised of pooled peripheral leucocytes isolated from $15250 \mathrm{~g}$ male 으 Wistar rats; and group 2 a concentrate of peripheral leucocytes from $15400 \mathrm{~g}$ rats of the same sex and strain. Each point on a curve represents the mean response from at least eight determinations. a migration of these cells was shown to be more susceptible to NSAID inhibitory action than that of the poly-O morphonuclear cell. This is in contrast to the results obtained from the present investigation in which the outer cell migratory boundary, consisting mainly of polymorphonuclear cells, was the area most vulner $\Omega$ able to drug action. A species difference may account $\overrightarrow{\overrightarrow{0}}$ for the disparity of results.

Using the Boyden chamber, Phelps and McCarty? (1967) showed that indomethacin suppressed the migration of canine and human polymorphonuclearo cells. Even though maximum inhibition occurred at $8 \times 10^{-7} \mathrm{~mol} / 1$ the suppressive activity persisted in drug concentrations as low as $1 \times 10^{-11} \mathrm{~mol} / 1$. These results vary with the ones reported in this study? where statistical migration inhibition induced by indomethacin was not seen below $5 \times 10^{-5} \mathrm{~mol} / 1$.

A phenomenon that was prevalent in the rat study and occasionally seen in the human experiments was= a stimulation of leucocyte migration. Lymphocytes in man constitute approximately $20-40 \%$ and poly morphonuclear cells $60-80 \%$ of the total leucocyte population, the converse being found in the rat.w Hydrocortisone in vitro has a dual action on huma:? leucocyte motility, the steroid stimulating the moves ment of total leucocytes, but inhibiting polymorpho nuclear cell migration (Stevenson, 1973). It may therefore be feasible that NSAID exert a selective stimulatory action on a predominantly lymphocyte population and an inhibitory action on a migrating? polymorphonuclear cell population. Experiments have begun to examine this possibility. 
How pertinent these in vitro results are to an in vivo action can only be speculated upon. In man, salicylate has been calculated to be clinically effective at blood levels of $25-30 \mathrm{mg} / 100 \mathrm{ml}$ (Ansell, 1963) and $30-50 \mathrm{mg} / 100 \mathrm{ml}$ (Smith et al., 1946), which is comparable with an in vitro concentration of $1 \cdot 7 \times 10^{-3} \mathrm{~mol} / 1$ to $2 \cdot 5 \times 10^{-3} \mathrm{~mol} / 1$, respectively. Similarly, on a molar basis, therapeutic concentrations of $3 \times 10^{-4} \mathrm{~mol} / 1$ phenylbutazone (Burns et al., 1953) and $1 \times 10^{-4} \mathrm{~mol} / 1$ ibuprofen (Adams, 1974) are frequently found. At these therapeutic levels cell motility in this study was not totally inhibited, but only partly suppressed, a situation analogous to the use of NSAID in rhematoid arthritis, where the disease is restrained but not arrested. From several reports stating the clinical effectiveness of indomethacin in blood to be approximately $1 \times 10^{-5}$ $\mathrm{mol} / 1$ to $1 \times 10^{-6} \mathrm{~mol} / \mathrm{l}$ (Caruso, 1971; Champion et al., 1972; Hvidberg et al., 1972) it appears that the inhibitory activity shown by this agent in vitro transgressed a therapeutic level.

Paracetamol induced inhibitory activity at concentrations surpassing those obtained in body fluids, while the ineffectiveness of para-hydroxybenzoic acid, in modifying leucocyte motility, added support to the hypothesis that an abrogation of cell migration by NSAID was an anti-inflammatory action.

Financial support for this work was given by Nicholas Aspro Limited.

\section{References}

Adams, S. S. (1974). Personal communication in article by Muirden, K. D., Deutshman, P., and Phillips, M. Competition between salicylate and other drugs in binding to human serum protein in vitro. Australian and New Zealand Journal of Medicine, 4, 149-153.

Ansell, B. M. (1963). Relationship of dosage and type of salicylate therapy to plasma levels in patients with rheumatoid arthritis. Salicylates-an International Symposium, pp. 35-37. Ed. by A. S. J. Dixon, B. K. Martin, M. J. H. Smith and P. H. N. Wood. Churchill, London.

Borel, J. F. (1973). Effect of some drugs on the chemotaxis of rabbit neutrophils in vitro. Experientia, 29, 676-678.

Burns, J. J., Rose, R. K., Chenkin, T., Goldman, A., Schubert, A., and Brodie, B. B. (1953). The physiological disposition of phenylbutazone in man and a method for its estimation in biological material. Journal of Pharmacology and Experimental Therapeutics, 109, 346-357.
Caruso, I. (1971). Verteilung von indometacin in blut und synovialflussigkeit chronischer polyarthritiker. Arzneimittelforschung, 21, 1824-1826.

Champion, G. D., Paulus, H. E., Mongan, E., Okun, R., Pearson, C. M., and Sorkissian, E. (1972). The effect of aspirin on serum indomethacin. Clinical Pharmacology and Therapeutics, 13, 239-248.

Di Rosa, M. (1974). Prostaglandin, leucocytes and nonsteroidal anti-inflammatory drugs. Polish Journal of Pharmacology and Pharmacy, 26, 25-36.

Di Rosa, M., Papadimitriou, J. M., and Willoughby, D. A. (1971). A histopathological and pharmacological analysis of the mode of action of non-steroidal anti-inflammatory drugs. Journal of Pathology, 105, 239-256.

George, M., and Vaughan, J. H. (1962). In vitro cell migration as a model for delayed hypersensitivity. Proceedings of the Society for Experimental Biology and Medicine, 111, 514-521.

Hvidberg, E., Lausen, H. H., and Jansen, J. A. (1972). Indomethacin: plasma concentrations and protein binding in man. European Journal of Clinical Pharmacology, 4, 119-124.

Keller, H. U., and Sorkin, E. (1968). Studies on chemotaxis. Inhibition of chemotaxis of rabbit polymorphonuclear leucocytes. International Archives of Allergy and Applied Immunology, 34, 513-520.

Maini, R. N., Roffe, L. M., Magrath, I. T., and Dumonde, D. C. (1973). Standardization of the leucocyte migration test. International Archives of Allergy and Applied Immunology, 45, 308-321.

Nakaniski, M., and Kazuhiro, G. (1974). Studies on antiinflammatory agents on leucocyte emigration in carrageenan-induced peritonitis of rats. Journal of the Pharmaceutical Society of Japan, 94, 1218-1223.

Phelps, P., and McCarty, D. J., Jr. (1967). Suppressive effects of indomethacin on crystal induced inflammation in canine joints and on neutrophilic motility in vitro. Journal of Pharmacology and Experimental Therapeutics, 158, 546-553.

Smith, P. R., Gleason, H. L., Stall, C. G., and Ogorzalek, S. (1946). Studies on the pharmacology of salicylates. Journal of Pharmacology and Experimental Therapeutics, 87, 237-243.

Stevenson, R. D. (1973). Hydrocortisone and the migration of human leucocytes: an indirect effect mediated by mononuclear cells. Clinical and Experimental Immunology, $14,417-426$.

Van Arman, C. G., Carlson, R. P., Brown, W. R., and Irkin, A. (1970). Indomethacin inhibits the local Schwartzman reaction. Proceedings of the Society for Experimental Biology and Medicine, 134, 163-168.

Van Arman, C. G., Bokelman, D. L., Risely, E. A., and Nuss, G. W. (1971). Changes in the rat's food with carrageenan inflammation and indomethacin treatment. (Abst.) Federation Proceedings, 30, 386.

Vinegar, R., Macklin, A. W., Traux, J. F., and Selph, J. L. (1971). Histopathological and pharmacological study of carrageenan inflammation in the rat. Pharmacologist, 13, 284-290. 